\title{
Elucidation of Lubrication Mechanism of Vegetable Oils and Their Effective Application
}

\author{
Teruo Murakami ${ }^{1)^{*}}$ and Hiroshi Sakamoto ${ }^{2)}$ \\ ${ }^{1)}$ Faculty of Engineering, Kyushu University \\ 744 Motooka, Nishi-ku, Fukuoka 819-0395, Japan \\ ${ }^{2)}$ Graduate School of Engineering, Kyushu University \\ 744 Motooka, Nishi-ku, Fukuoka 819-0395, Japan \\ *Corresponding author: tmura@mech.kyushu-u.ac.jp
}

( Manuscript received 1 July 2008; accepted 14 August 2008; published 15 October 2008 )

( Presented at JAST Tribology Conference in Tokyo, May 2008 )

\begin{abstract}
From the viewpoint of natural environmental requirement, the applications of biodegradable lubricants are growing. Most of vegetable oils are biodegradable and have good lubricating performance even at high contact pressure conditions in spite of their lower pressure-viscosity coefficient. In vegetable oils, however, the optimum suppression of oxidative degradation is required to improve the longevity of vegetable oils. Therefore, it is required to clarify the actual lubrication mechanism in vegetable oils with appropriate antioxidant additives. In this study, the tribological properties of four kinds of vegetable oils of different composition were evaluated in four-ball tests at different sliding speed conditions. As an antioxidant additive, $\alpha$-tocopherol was used. The types of fatty acids in triglycerides appeared to control the lubricating performance through adsorbed film and friction polymer formation, depending on the operating conditions. Therefore, the paraffinic oils containing fatty acid were tested. It was shown that the influences of fatty acid types on lubricating performance were different depending on sliding speeds. These differences are discussed from the viewpoints of the role of friction polymer and oxidation of oils evaluated by FTIR analyses. Finally, effective application of various vegetable oils is discussed on the basis of relationship between tribological behaviors and operating conditions.
\end{abstract}

Keywords: biodegradable oil, vegetable oil, friction polymer, antioxidant additive, unsaturated fatty acid

\section{Introduction}

Recent strategies of good practice for sustainability with global natural environment impose various tasks such as application of biodegradable oils and minimum usage of lubricants. The vegetable oils such as rapeseed oil and castor oil are biodegradable, inexpensive and have good lubricating performance even at high contact pressure conditions in spite of their lower pressure-viscosity coefficient ${ }^{1)}$. The vegetable oils are originated from various vegetables and composed of triglycerides with various fatty acids. The lubricating performance of vegetable oils changes depending on the operating conditions. Furthermore, the appropriate suppression of oxidative degradation is an unsolved subject to improve the longevity of vegetable oils.

Therefore, it is required to clarify the actual lubrication mechanism in vegetable oils different in composition with and without antioxidant additive. These results can be reflected to the development of the new biodegradable synthetic lubricants, although expensive synthetic oils such as polyolpolyester have appropriate biodegradability and lubricating performance.

In our previous paper ${ }^{2}$, the frictional characteristics and load-carrying capacity of vegetable oils were evaluated in four-ball tests under increasing-temperature conditions at $1 \mathrm{rpm}$ (sliding speed $=0.58 \mathrm{~mm} / \mathrm{s}$ ). The main constituents of vegetable oils are triglycerides as esters of glycerol and fatty acids. To understand the basic tribological properties of constituents, the lubricating performance of glycerol with or without fatty acid was investigated. As fatty acids, stearic acid and linolenic acid were used. As shown in Fig. 1, glycerol alone showed poor lubricating property, but the addition of fatty acid remarkably improved the frictional behaviors. The stearic acid as a saturated acid exhibited good lubricating property at lower temperature than $120^{\circ} \mathrm{C}$, but friction increased above this transition temperature, which corresponds to the boundary lubrication property 


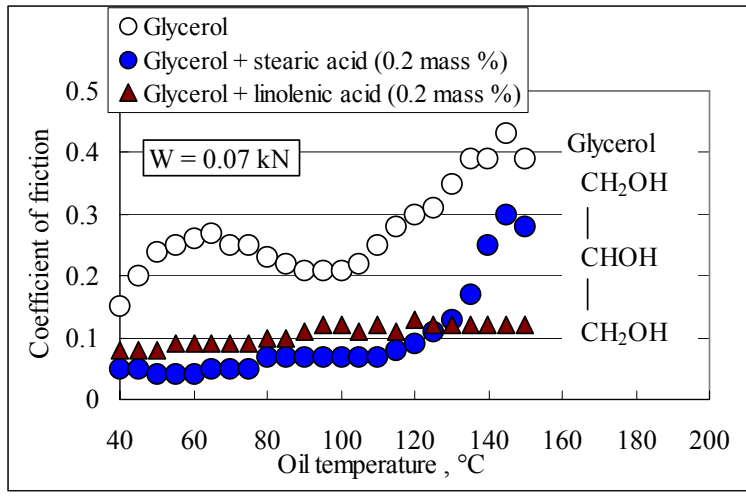

Fig. 1 Effect of fatty acid on frictional behavior of glycerol at low speed condition in four-ball tests ${ }^{2)}$

by adsorbed film of saturated fatty acid $^{3)}$. In contrast, the unsaturated linolenic acid showed a little higher friction in low temperature range but maintained low friction at higher temperature.

Similar friction-temperature characteristics were observed in synthetic paraffinic oils with saturated or unsaturated fatty acids ${ }^{2}$. These results appear to reflect the difference in the lubricating roles of fatty acid types in triglycerides of vegetable oils. In other words, it is considered that the saturated fatty acid types are effective at lower temperature than the transition temperature for the corresponding soap films but the unsaturated fatty acid types preserve the low friction property at high temperature range, probably due to tribochemical reactions, which is indicated by the observation of friction polymer on rubbing surfaces.

The majority of fatty acids in glycerides are unsaturated fatty acids such as oleic, linoleic and linolenic acids. And the activated parts in unsaturated fatty acids and dissolved oxygen appear to promote the reaction and/or oxidation of oils. To improve both the oxidative stability and load-carrying capacity of these lubricants, the appropriate antioxidant additives are required.

In this paper, the tribological properties of four kinds of vegetable oils of different composition were evaluated in four-ball tests at different sliding speed conditions to elucidate the lubrication mechanism. As antioxidant additive, $\alpha$-tocopherol (vitamin E) was used. The types of fatty acids in triglycerides appeared to control the lubricating performance, depending on the operating conditions. Therefore, the paraffinic oils containing fatty acid were tested to examine the influences of fatty acid types on the lubricating performance.

These differences in friction and load-carrying capacity are discussed from the viewpoints of the role of friction polymer and oxidation of oils evaluated by FT-IR analyses. Finally, effective application of various vegetable oils is discussed on the basis of the relationship between tribological behaviors and operating conditions.

\section{Experimental method}

The four-ball tests were carried out under the increasing-temperature condition at a constant rate of 10 ${ }^{\circ} \mathrm{C} / \mathrm{min}$ under the constant load at $1 \mathrm{rpm}$ (sliding speed $=$ $0.58 \mathrm{~mm} / \mathrm{s}$ ) and at $200 \mathrm{rpm}$ (sliding speed $=116 \mathrm{~mm} / \mathrm{s}$ ) to evaluate the lubricating properties at different lubricating film thickness under high contact pressure conditions. Test ball for Soda-type tester is bearing steel (SUJ 2, JIS) of $19.05 \mathrm{~mm}$ diameter. The frictional behavior at the constant load was observed to evaluate the scuffing load, which is defined as the load where the continuous stick slip occurs, the friction abruptly increases or friction noise becomes clearly audible during running until $200{ }^{\circ} \mathrm{C}$. The normal load $W$ in each test was increased at the step of about $0.1 \mathrm{kN}$ for lower load range or $0.2 \mathrm{kN}$ for higher load by changing the hydraulic pressure. The repeatability of scuffing load was confirmed by the second test at the same load. The results at higher or lower load around the scuffing load can support the repeatability.

Friction and load-carrying properties for four kinds of vegetable oils, i.e., olive, rapeseed, soybean and linseed oils with low viscosity $\left(25-38 \mathrm{~mm}^{2} / \mathrm{s}\right.$ at $40{ }^{\circ} \mathrm{C}$, Table 1) and structures with different fatty acid types (Table 2, Fig. 2) were compared with those of synthetic paraffinic oil (P-B300) with or without fatty acid (0.4 mass \%). P-B300 is a wide-ranged blended paraffinic oil of poly- $\alpha$-olefin (PAO-6) and ethylene-olefin co-oligomer $(\mathrm{HC}-100)^{2}$.

The olive oil contains high quantity of triglyceride derived from glycerol and oleic acid of C18 unsaturated molecule of a double-bond, whereas the rapeseed oil is

Table 1 Properties of vegetable oils and paraffinic oil

\begin{tabular}{|c|c|c|c|c|c|}
\hline Oils & $\begin{array}{l}\text { Olive } \\
\text { oil }\end{array}$ & $\begin{array}{l}\text { Rapeseed } \\
\text { oil }\end{array}$ & $\begin{array}{l}\text { Soybean } \\
\text { oil }\end{array}$ & $\begin{array}{l}\text { Linseed } \\
\text { oil }\end{array}$ & P-B300 \\
\hline $\begin{array}{l}\text { Density } \\
\mathrm{g} / \mathrm{cm}^{3} \\
\left(15^{\circ} \mathrm{C}\right)\end{array}$ & 0.914 & 0.919 & 0.921 & 0.931 & 0.837 \\
\hline $\begin{array}{c}\text { Kinematic } \\
\text { viscosity } \\
\mathrm{mm}^{2} / \mathrm{s}\end{array}$ & $\begin{array}{l}38.0 \\
\left(40^{\circ} \mathrm{C}\right) \\
8.2^{\circ} \\
\left(100^{\circ} \mathrm{C}\right)\end{array}$ & $\begin{array}{l}33.2 \\
7.8\end{array}$ & $\begin{array}{l}30.4 \\
7.2\end{array}$ & $\begin{array}{l}24.8 \\
6.3\end{array}$ & $\begin{array}{l}292.1 \\
33.3\end{array}$ \\
\hline
\end{tabular}

Table 2 Fatty acid types in structure of vegetable oils

\begin{tabular}{|l|l|l|l|l|l|l|}
\hline & $\begin{array}{l}\text { Palmitic } \\
\text { acid } \\
(\mathrm{C} 16: 0)\end{array}$ & $\begin{array}{c}\text { Stearic } \\
\text { acid } \\
(\mathrm{C} 18: 0)\end{array}$ & $\begin{array}{c}\text { Oleic } \\
\text { acid } \\
\mathrm{C} 18: 1\end{array}$ & $\begin{array}{c}\text { Linoleic } \\
\text { acid } \\
\mathrm{C} 18: 2)\end{array}$ & $\begin{array}{l}\text { Linolenic } \\
\text { acid } \\
(\mathrm{C} 18: 3)\end{array}$ & Remarks \\
\hline Olive oil & $11.2 \%$ & $0.9 \%$ & $\begin{array}{l}85.9 \\
\%\end{array}$ & $2 \%$ & & \\
\hline $\begin{array}{l}\text { Rapesed } \\
\text { oil }\end{array}$ & $3 \%$ & $1 \%$ & $29 \%$ & $20 \%$ & $7 \%$ & $\begin{array}{l}\text { Erucic acid } \\
(\mathrm{C} 22: 1) \\
27 \% \\
\text { Other } 13 \%\end{array}$ \\
\hline $\begin{array}{l}\text { Soybean } \\
\text { oil }\end{array}$ & & & $24 \%$ & $55 \%$ & $8 \%$ & $\begin{array}{l}\text { Other } \\
13 \%\end{array}$ \\
\hline $\begin{array}{l}\text { Linseed } \\
\text { oil }\end{array}$ & & & $22 \%$ & $16 \%$ & $52 \%$ & $\begin{array}{l}\text { Other } \\
10 \%\end{array}$ \\
\hline
\end{tabular}

(*Numerals mean numbers of carbon and double bond) 


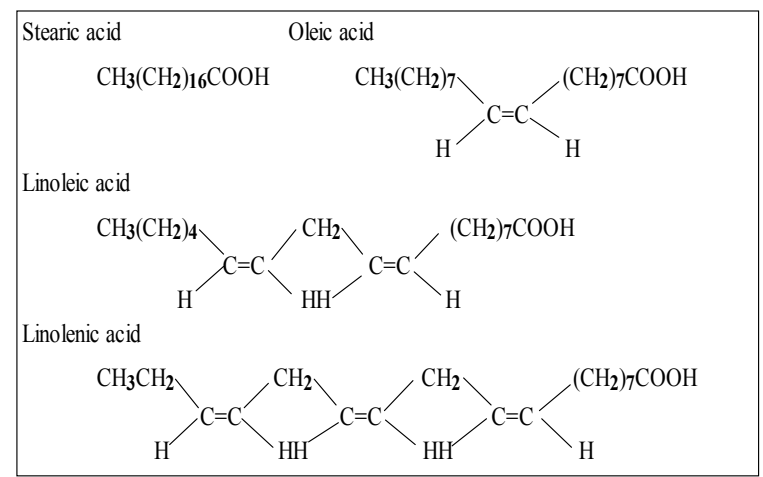

Fig. 2 Structures of main saturated and unsaturated fatty acids

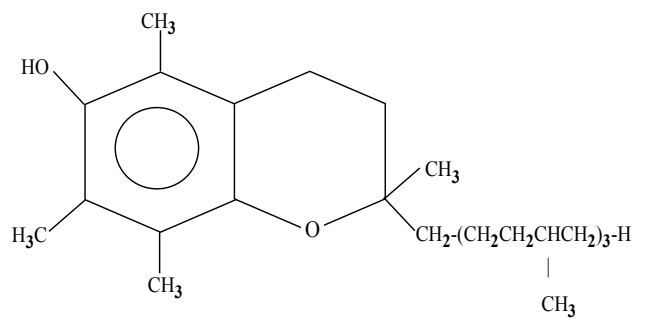

Fig. $3 \alpha$-tocopherol (Vitamin E) as antioxidant

derived from oleic acid and erucic acid of $\mathrm{C} 22$ with a double-bond, and some linoleic and linolenic acids of C18 unsaturated fatty acids of 2 and 3 double-bonds in the ester structure, respectively. Here, most of commercially used rapeseed oils are composed of different fatty acid types, and thus additional tests for another rapeseed oil are required in future study.

Furthermore, it is noticed that a soybean oil cotains plenty of linoleic acid type and a linseed oil has plenty of linolenic acid type.

The oxidation is considered to play an important role in the formation of friction polymer, oxide film formation, and stability of vegetable oils. Therefore, $\alpha$-tocopherol (vitamin E, Fig. 3) was added with 1.0 mass $\%$ as an antioxidant, which is contained in natural vegetable oils.

Next, to elucidate the lubrication mechanism by fatty acids, the temperature-raising four-ball tests for P-B300 with or without fatty acids were conducted under conditions with or without anti-oxidant additives.

For examination of formation of friction polymer ${ }^{4}$ on rubbing surfaces, FT-IR analysis was applied for the square area of $0.6 \mathrm{~mm} \times 0.6 \mathrm{~mm}$.

\section{Results and discussion}

\subsection{Frictional behaviors at low speed}

Frictional behaviors of vegetable oils at low sliding speed of $0.58 \mathrm{~mm} / \mathrm{s}$ and high load of $0.47 \mathrm{kN}$ (mean contact pressure: $p_{\mathrm{a}}=2.49 \mathrm{GPa}$ ) are shown in Fig. 4 . The olive oil maintained low friction at low temperature, but friction increased at high temperature. In contrast, the soybean oil shows a little higher friction at low temperature range but maintains considerable low friction at higher temperature. The former contains plenty of oleic acid type in ester structure, but the latter has plenty of esters derived from unsaturated fatty acids including linoleic and oleic acids. Thus, the difference in fatty acid types appears to bring the difference in friction in these temperature ranges.

For rapeseed and linseed oils, however, friction increasing behaviors were observed. Rapeseed oil showed a friction increase above $80{ }^{\circ} \mathrm{C}$ and then a friction decrease at high temperature.

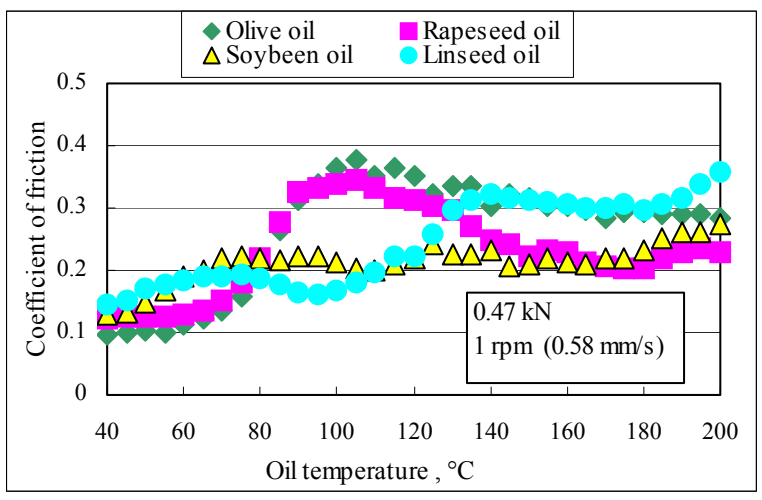

Fig. 4 Frictional behaviors of vegetable oils at $0.58 \mathrm{~mm} / \mathrm{s}$

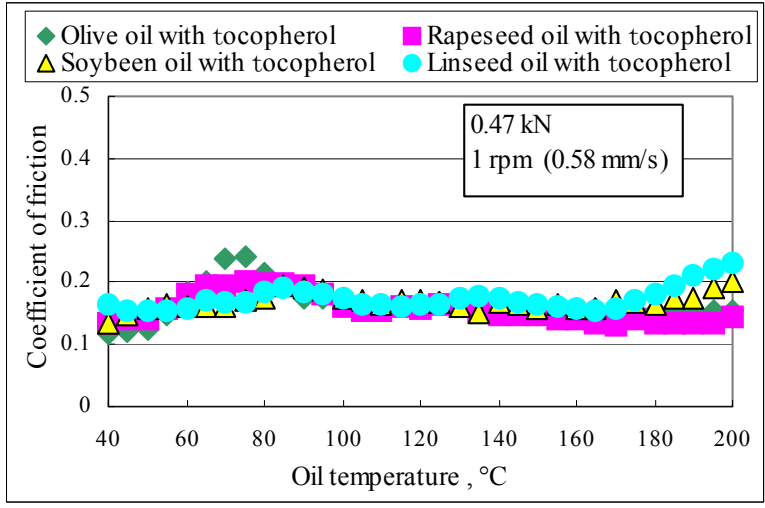

Fig. 5 Influence of $\alpha$-tocopherol on frictional behaviors of vegetable oils at $0.58 \mathrm{~mm} / \mathrm{s}$

It is noticed that linseed oil containing plenty of linolenic acid type showed remarkable increase above $120{ }^{\circ} \mathrm{C}$. At low speed condition which corresponds to boundary lubrication regime, the formation of adsorbed film and friction polymer on rubbing surfaces appears to control the frictional behaviors. The unsaturated fatty acids, particularly linolenic acid with 3 double bonds and linoleic acid with 2 double bonds are usually expected to easily form friction polymer. For linseed oil, however, excessive formation of friction polymer may hinder the entraining of oils.

Next, the $\alpha$-tocopherol as an antioxidant was added. As shown in Fig. 5, it is noticed that all vegetable oils showed considerable low friction in all temperature 
range. For three oils containing linleic and/or polymer controlled by an antioxidant appears to become effective. For friction reduction of the olive oil in high temperature range which is unable to form sufficient friction polymer, the adsorbed film formation by $\alpha$-tocopherol might become effective to facilitate running-in. This phenomenon should be explored in future study.

Next, the frictional behaviors of paraffinic oils P-B300 with and without fatty acid at low sliding speed of $0.58 \mathrm{~mm} / \mathrm{s}$ and load of $0.17 \mathrm{kN}\left(p_{\mathrm{a}}=1.77 \mathrm{GPa}\right)$ are shown in Fig. 6. P-B300 without fatty acid shows friction increase above $80{ }^{\circ} \mathrm{C}$, in spite of higher viscosity than vegetable oils.

The addition of stearic acid reduced friction in low temperature range but its friction turns to increase above $110^{\circ} \mathrm{C}$. At high temperature range, the friction became higher than P-B300. The addition of oleic acid exhibits similar frictional behavior. On the contrary, the addition of linoleic or linolenic acid could preserve low friction in all temperature range. These phenomena correspond to the results for glycerol with fatty acid (Fig. 1).

To examine the effect of an antioxidant, $\alpha$-tocopherol was added to these oils. Friction of P-B300 at high temperature range above $150{ }^{\circ} \mathrm{C}$ was reduced (Fig. 7). But, the friction at high temperature range of

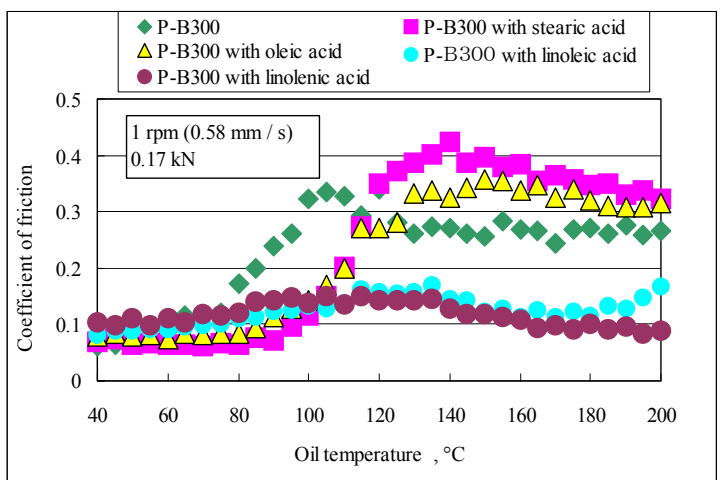

Fig. 6 Frictional behaviors of paraffinic oil with and without fatty acids at $0.58 \mathrm{~mm} / \mathrm{s}$

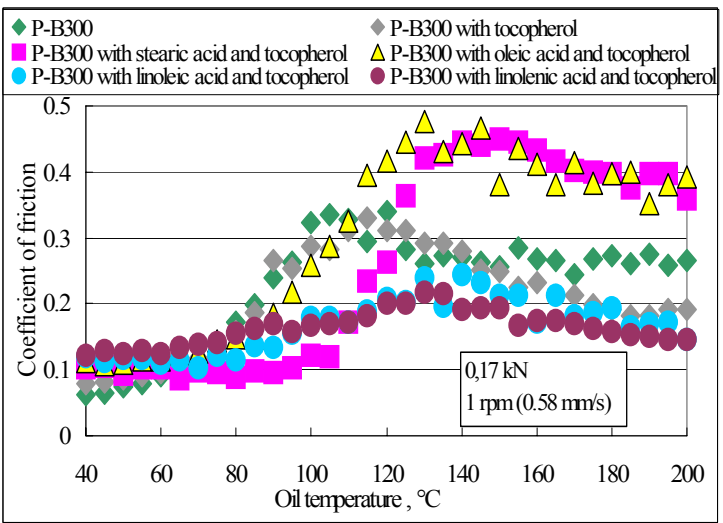

Fig. 7 Influence of $\alpha$-tocopherol on frictional behaviors of paraffinic oils at $0.58 \mathrm{~mm} / \mathrm{s}$
100-200 ${ }^{\circ} \mathrm{C}$ of P-B300 with fatty acids was increased. Antioxidant seems to suppress the formation of friction polymer.

\subsection{Frictional behaviors at high speed}

Frictional behaviors of vegetable oils at high sliding speed of $116 \mathrm{~mm} / \mathrm{s}$ and high load of $0.57 \mathrm{kN}\left(p_{\mathrm{a}}=2.68\right.$ $\mathrm{GPa}$ ) are shown in Fig. 8. At this speed, some elastohydrodynamic film formation becomes effective with local direct contact but frictional heat generates local temperature increase. Under this condition, in soybean and linseed oils the scuffing occurred at $120^{\circ} \mathrm{C}$.

For vegetable oils added with $\alpha$-tocopherol, in linseed oil the scuffing still occurred, as shown in Fig. 9. Frictional behaviors of P-B300 with and without fatty acid are shown in Fig. 10. At this load, the scuffing occurred for P-B300 and with oleic acid. For oils with $\alpha$-tocopherol, the scuffing occurred P-B300 and with linoleic and linolenic acids (Fig. 11).

\subsection{Load-carrying capacity}

Scuffing load of vegetable oils at $0.58 \mathrm{~mm} / \mathrm{s}$ and 116 $\mathrm{mm} / \mathrm{s}$ are shown in Fig. 12. At low speed, the soybean oil showed higher scuffing load. The addition of $\alpha$-tocopherol enhanced the scuffing load of all vegetable oils. At high speed, olive oil exhibited the highest scuffing load, and the increase of double bond reduced the scuffing load. The addition of $\alpha$-tocopherol

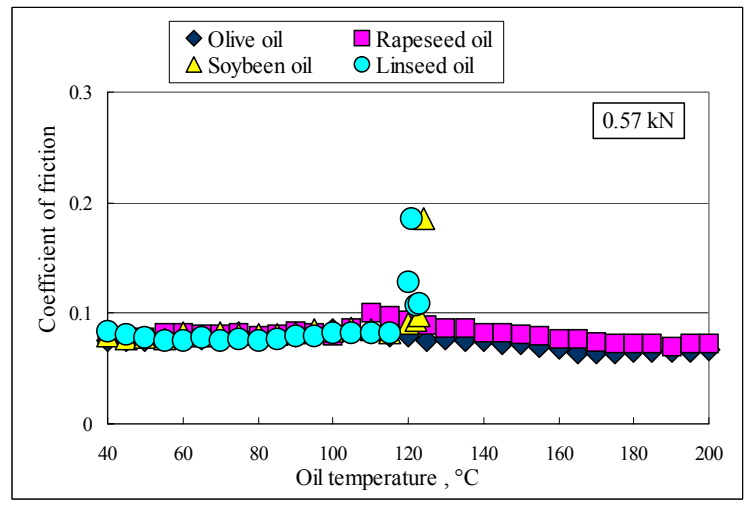

Fig. 8 Frictional behaviors of vegetable oils at 116 $\mathrm{mm} / \mathrm{s}$

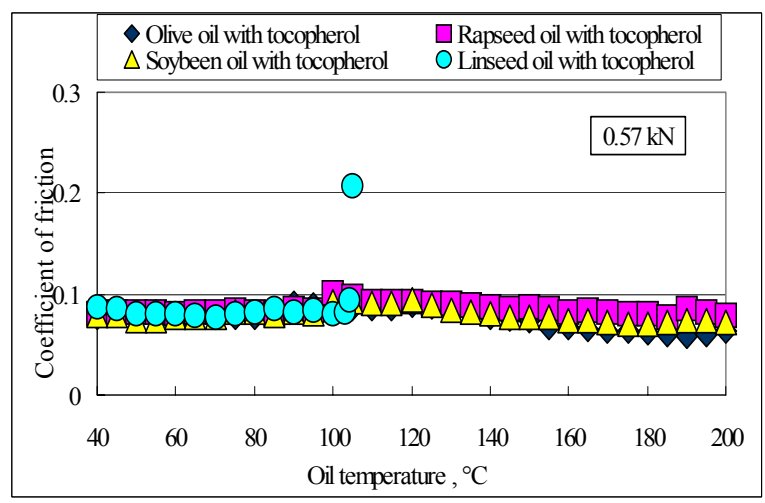

Fig. 9 Influence of $\alpha$-tocopherol on frictional behaviors of vegetable oils at $116 \mathrm{~mm} / \mathrm{s}$ 


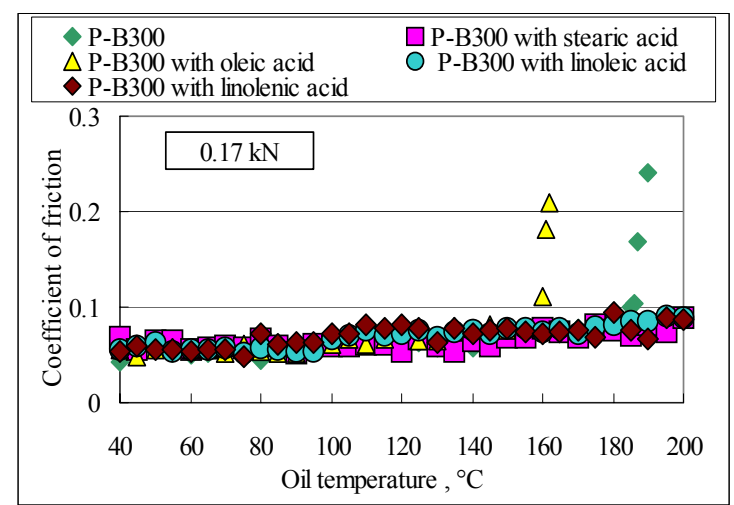

Fig. 10 Frictional behaviors of paraffinic oil with and without fatty acids at $116 \mathrm{~mm} / \mathrm{s}$

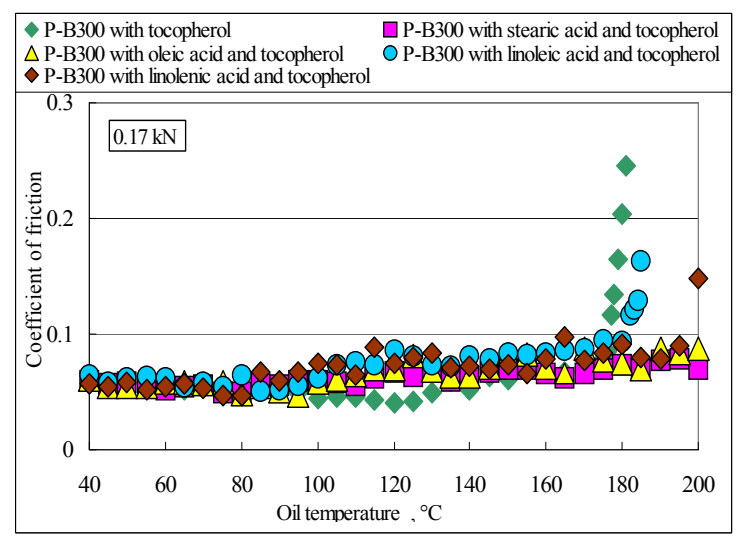

Fig. 11 Influence of $\alpha$-tocopherol on frictional behaviors of paraffinic oils at $116 \mathrm{~mm} / \mathrm{s}$

improved the load-carrying capacity of soybean and linseed oils.

The scuffing loads of P-B300 with and without fatty acids are shown in Fig. 13. At low speed, the increase in double bond of fatty acid remarkably enhanced the load-carrying capacity, but the addition of $\alpha$-tocopherol suppressed the effect of unsaturated fatty acid. At high speed, the effect of fatty acid at 0.4 mass $\%$ was not so much.

\subsection{FT-IR analysis of rubbing surfaces}

In our previous paper ${ }^{2)}$ on low speed four-ball tests, FT-IR analysis for rubbing surface indicated that friction polymer was formed with tribochemical oxidation and effective for surface protection.

Therefore, the rubbing surfaces for vegetable oils at high speed tests were examined by FT-IR. Figure 14 shows FT-IR data for square area within wear scar for vegetable oils at $0.37 \mathrm{kN}$. Significant IR absorption is observed around $1400-1800 \mathrm{~cm}^{-1}$ and $2900 \mathrm{~cm}^{-1}$. The absorption zones around 1465, 1590 and $1760 \mathrm{~cm}^{-1}$ appear to correspond to $-\mathrm{CO} \cdot \mathrm{O}-\mathrm{CH}_{2}$, $-\mathrm{CO}-\mathrm{CH}_{2}-\mathrm{CO}-$ and $-\mathrm{CH}_{2}-\mathrm{COO} \cdot \mathrm{R}$, respectively, although $1710 \mathrm{~cm}^{-1}$ indicates $-\mathrm{CH}_{2}-\mathrm{COOH}$. The zones at 2850, 2925 and $2960 \mathrm{~cm}^{-1}$ correspond to $-\mathrm{CH}_{2}-,-\mathrm{CH}_{2}-$ and $-\mathrm{CH}_{3}$. This fact indicates that

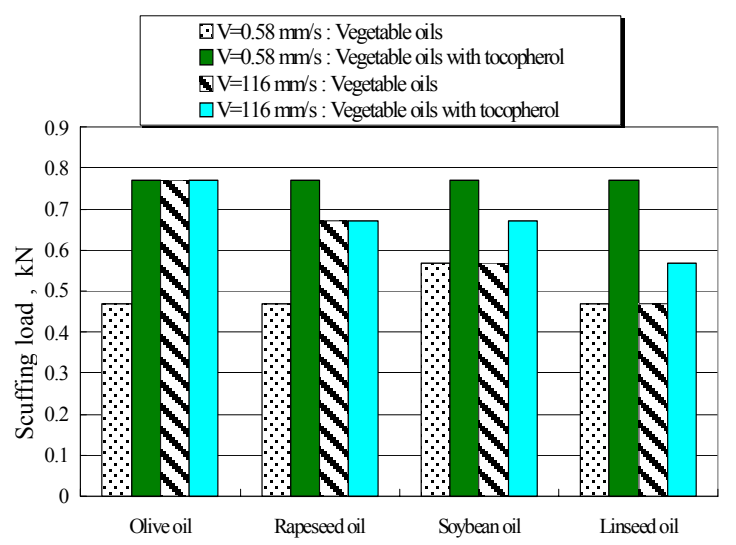

Fig. 12 Scuffing load of vegetable oils

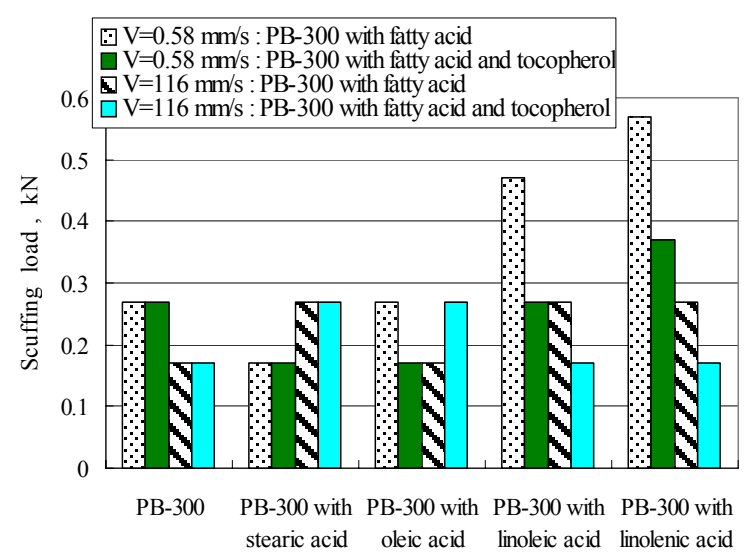

Fig. 13 Scuffing load of P-B300 with and without fatty acids.

friction polymer was formed with oxidation. It is noticed that olive oil shows inferior formation of friction polymer. The other 3 oils exhibit excessive film formation as black film around wear scar (Fig.14), which appears to hinder the entrainment of lubricating oil. In wear scar, the leading edge is left side.

Figure 15 indicated that the addition of $\alpha$-tocopherol suppresses the absorption particularly for $1400-1800$ $\mathrm{cm}^{-1}$, which means the suppression of the oxidation and surface film formation. The excessive accumulation of friction polymer around wear scar was appropriately suppressed as shown in Fig. 15.

\subsection{Effective application of vegetable oils}

From these four-ball tests at low speed corresponding to boundary lubrication regime, the superior lubricating performance of vegetable oils with considerable unsaturated fatty acid types was shown and the effectiveness of unsaturated fatty acid in paraffinic oil was demonstrated. The appropriate friction polymer formation appears to play the protective role at higher temperature ${ }^{2)}$. The simple heating of oil inducing bulk oxidation is unlikely to form the protective surface film equal to friction polymer. For actual use of these oils, the optimum preparation with appropriate oxidative 


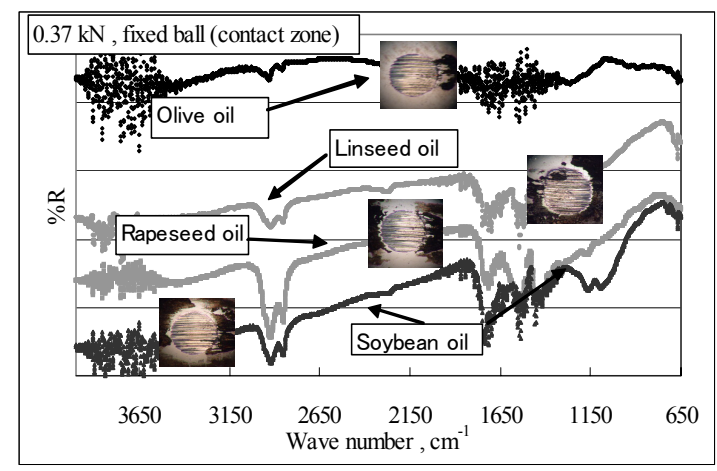

Fig. 14 FT-IR for vegetable oils on wear scars

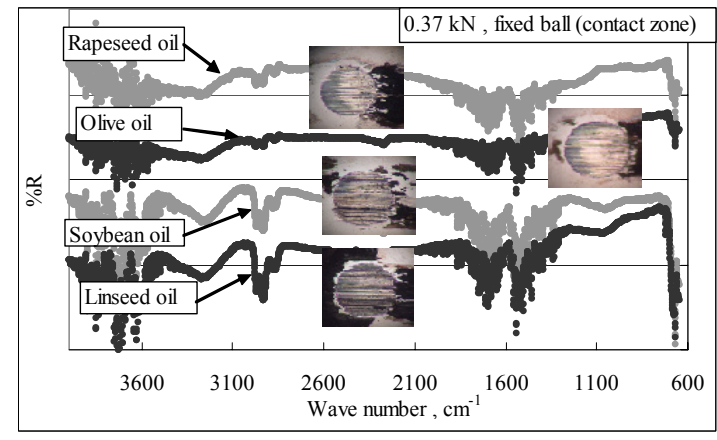

Fig. 15 Influence of $\alpha$-tocopherol on FT-IR

stability controlled by antioxidant such as $\alpha$-tocopherol should be taken into consideration with effectiveness of tribochemical reaction for formation of friction polymer.

In various rubbing surfaces of machines and tribological devices, the sliding motions at high speeds induce the temperature rising, which has an influence on the oxidation of oils and the formation of friction polymer. In temperature-increasing four-ball tests at 10 ${ }^{\circ} \mathrm{C} / \mathrm{min}$ and high speed in this study, the olive oil containing plenty of oleic acid showed the highest load-carrying capacity. Vegetable oils with unsaturated fatty acid types of two and three double bonds showed inferior load-carrying capacity because of excessive formation of friction polymer. When we changed the temperature increasing condition to $5{ }^{\circ} \mathrm{C} / \mathrm{min}$, however, the order of scuffing load at $116 \mathrm{~mm} / \mathrm{s}$ was changed to soybean $>$ linseed $>$ rapeseed $>$ olive oils ${ }^{5}$. Thus, the effectiveness of friction polymer depends on the severity of operating conditions. Therefore, appropriate selection of vegetable oils with different fatty acid types corresponding to the severity of operating conditions becomes important.

\section{Conclusion}

In the temperature-increasing four-ball tests at low and high speeds, the lubricating performance of vegetable oils, and paraffinic oil with or without fatty acid were evaluated. In these oils, the lubricating roles of fatty acid types in triglycerides were discussed from the difference of friction polymer formation with unsaturated fatty acids. The effectiveness of unsaturated fatty acid types in vegetable oils was different depending on the sliding speeds. It was shown for paraffinic oil that the addition of linolenic acid with three double bonds was the most effective at low speed. The addition of $\alpha$-tocopherol played an important role in controlling of tribochemical oxidation.

On the basis of the observation of surface film on the rubbing surfaces and FT-IR analysis, it was indicated that the appropriate formation of friction polymer brought low friction and high load-carrying capacity. The addition of antioxidant additives suppressed the formation of friction polymer. The optimum condition between the load-carrying capacity and the longevity of lubricants should be considered in related to the severity of operating conditions.

\section{Acknowledgment}

The authors wish to thank Nippon Steel Chemical Co. Ltd. for providing of paraffinic oil.

\section{References}

[1] Ohno, N., Shiratake, A., Kuwano, N. and Hirano, F. "Behavior of Some Vegetable Oils in EHL Contacts," Elastohydrodynamics - '96: Fundamentals and Applications in Lubrication and Traction, Ed. by Dowson, D. et al., Elsevier B. V., Amsterdam, 1997, 243-251.

[2] Murakami, T. and Sakamoto, H., "Lubricating Properties of Vegetable Oils and Paraffinic Oils with Unsaturated Fatty Acids under High Contact Pressure Conditions in Four-Ball Tests," J. Synthetic Lubrication, 20, 2003, 183-201.

[3] Bowden, F. P. and Tabor, D., The Friction and Lubrication of Solids, Clarendon Press, Oxford, 1950, 200.

[4] Hu, Z., Tao, D. and Wang R.-L., "Functional Mechanism of Formation of Friction Polymer with Dihydroxydocosanoic Acid," Lubrication Science, 7, 3, 1995, 285-290.

[5] Sakamoto, H. and Murakami, T., "Optimum Operating Conditions of Various Vegetable Oils in Temperature Rising Four-Ball Tests," Proc. JAST Tribology Conference Tokyo, May, 2008, 287-288. 